\title{
Drilling induced borehole breakouts - new insights from LWD data analysis
}

\author{
K. Stricker, S. Schimschal, T. Kohl, J. Meixner, B. Müller and S. Wessling $\bowtie$ kai.stricker@kit.edu
}

\section{Motivation}

- Azimuthal LWD logs provide images of the borehole wall, which are widely used for the analysis of borehole breakouts

- These breakouts develop when the circumferential stress around the borehole wall exceeds the compressive strength of the rock

- Uncertainty on how drilling processes (such as tripping) influence the development of breakouts

\section{Theoretical background}

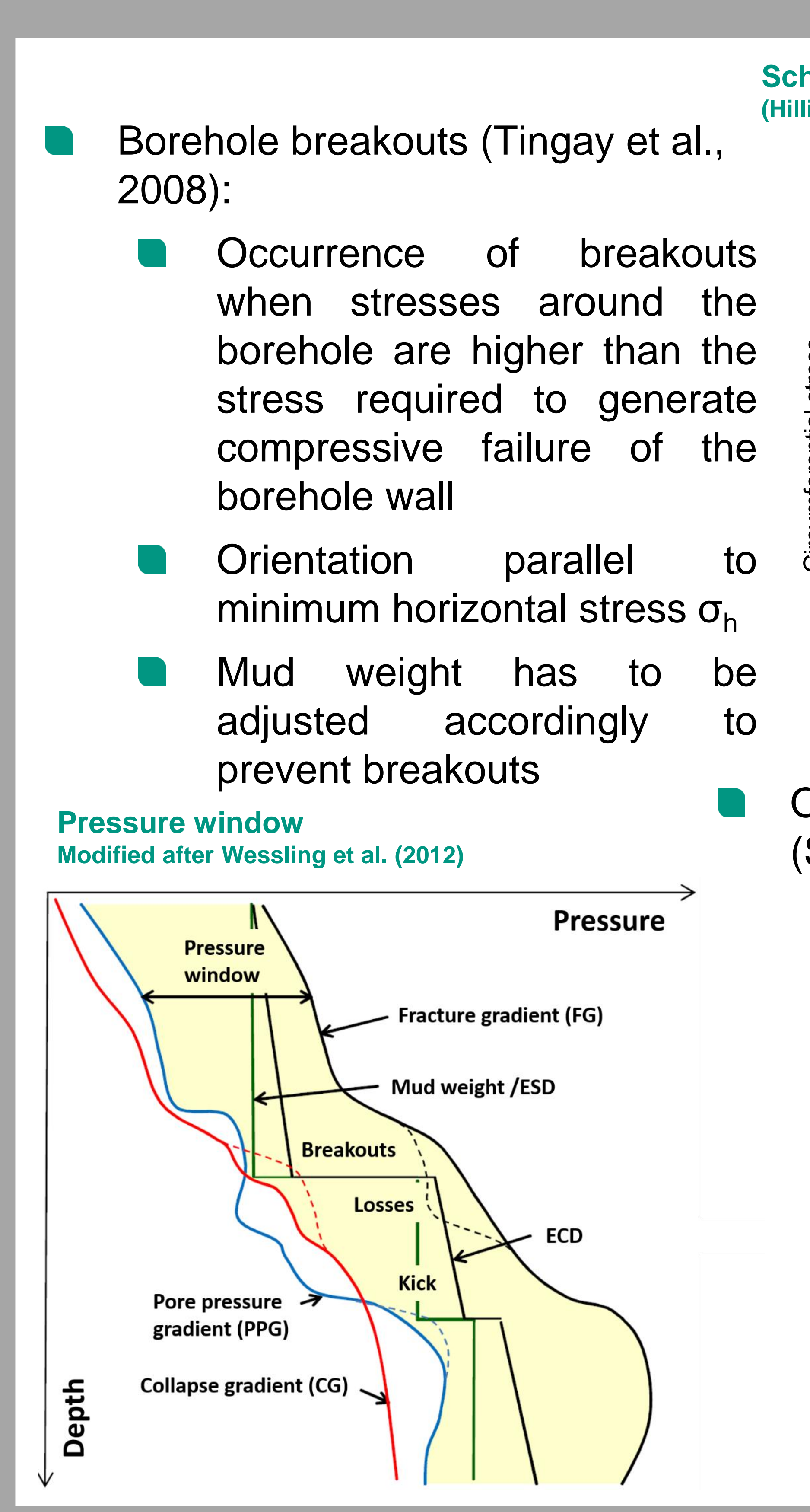

Schematic cross sections of borehole breakouts
(Hillis and Reynolds, 2000)

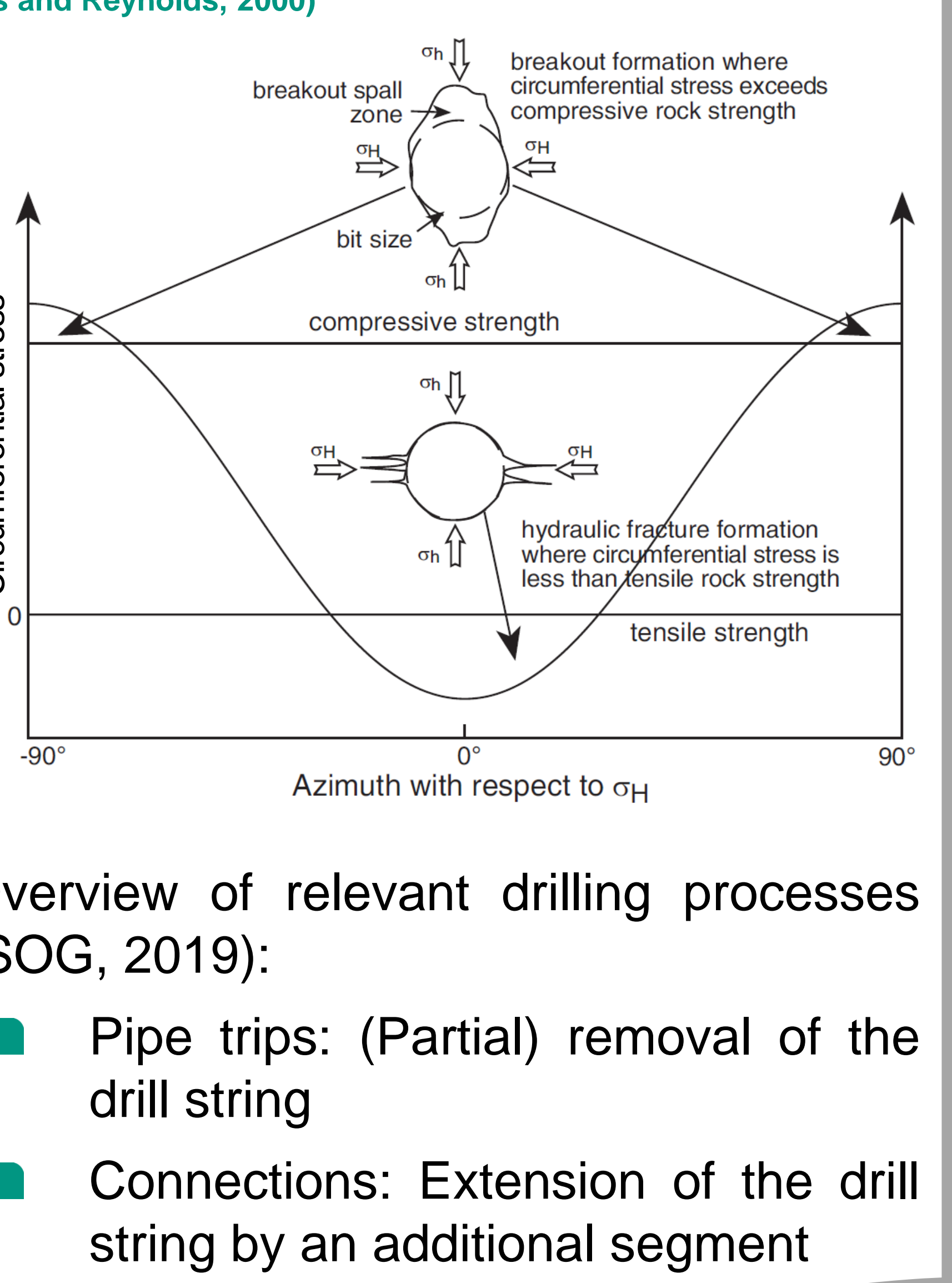

\section{Conclusion and Perspectives}

- Observation of a relation between drilling processes and breakouts

- Negative pressure variations may have contributed to the development of breakouts

- Breakouts tend to grow both azimuthally and in their depth extent

- Future research could benefit from the availability of relogs and/or multiple image logging tools in the same wellbore

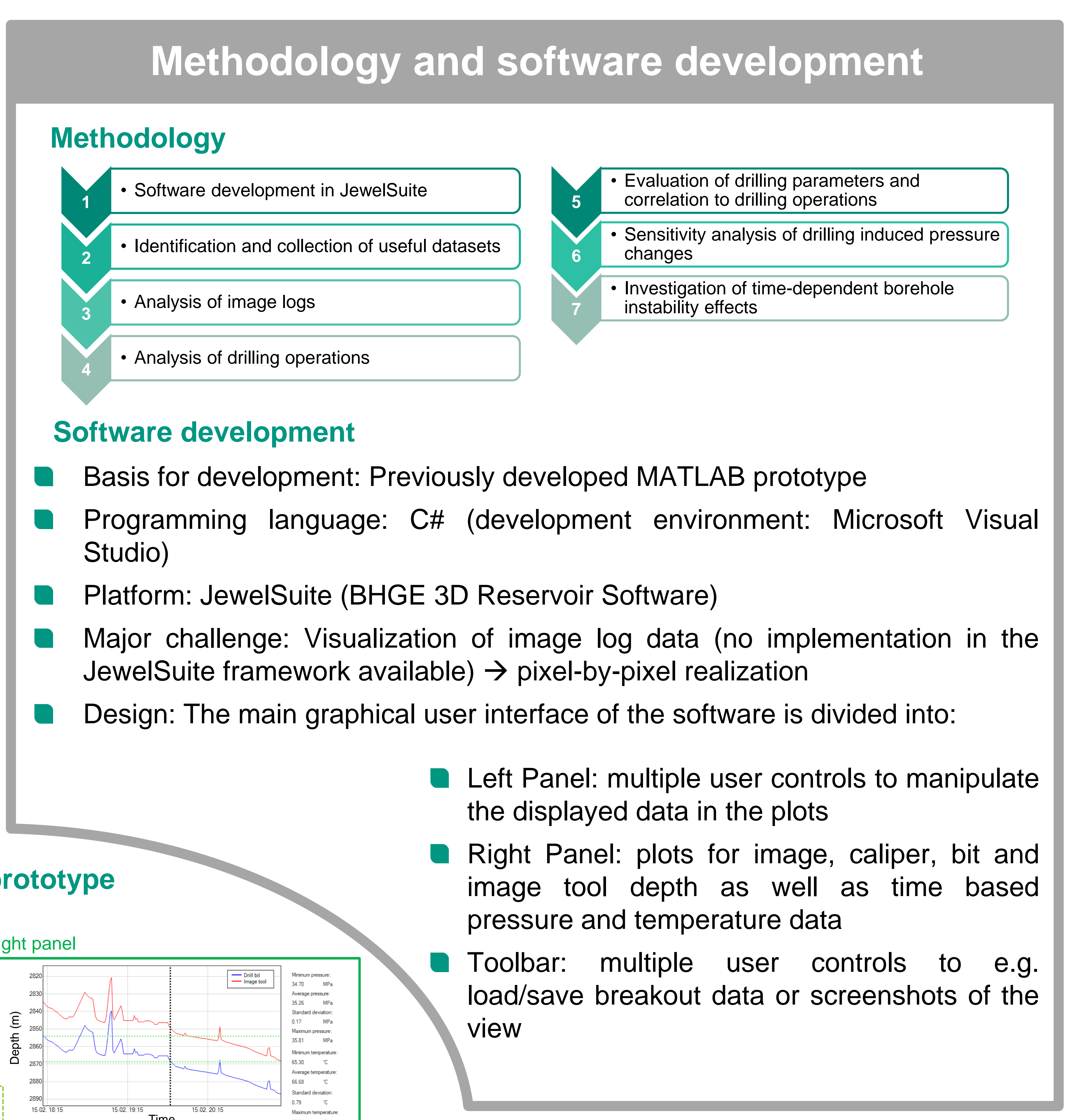

Influence of drilling processes

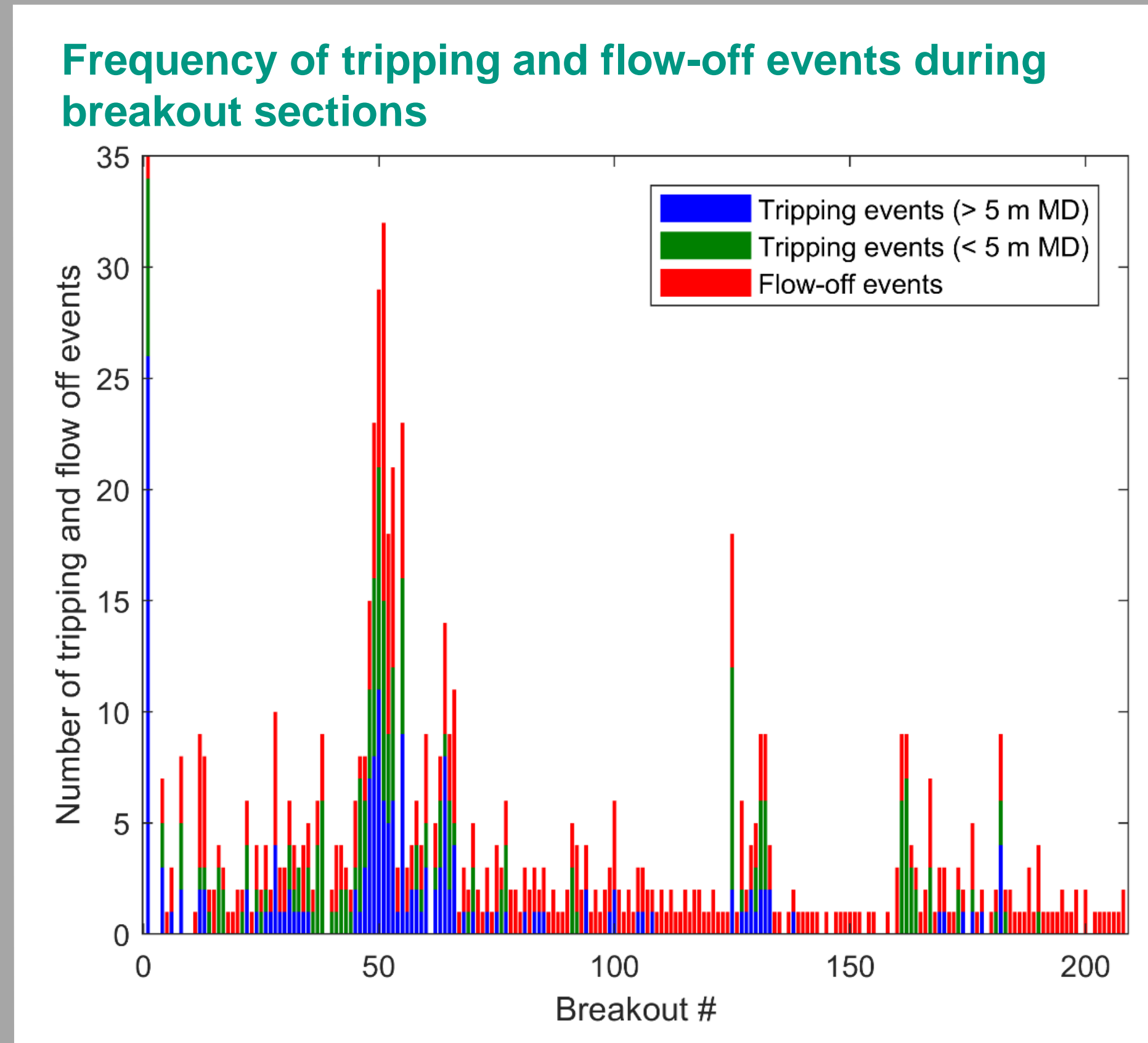

- Clear relation between breakouts and tripping operations / flow-off events $\rightarrow$ Cause for occurrence?

- Frequency of tripping events within breakout intervals one order of magnitude higher than outside

- Flow-off events (switched-off pumps) also occur more frequently within breakout intervals

$$
\text { string by an additional segment }
$$

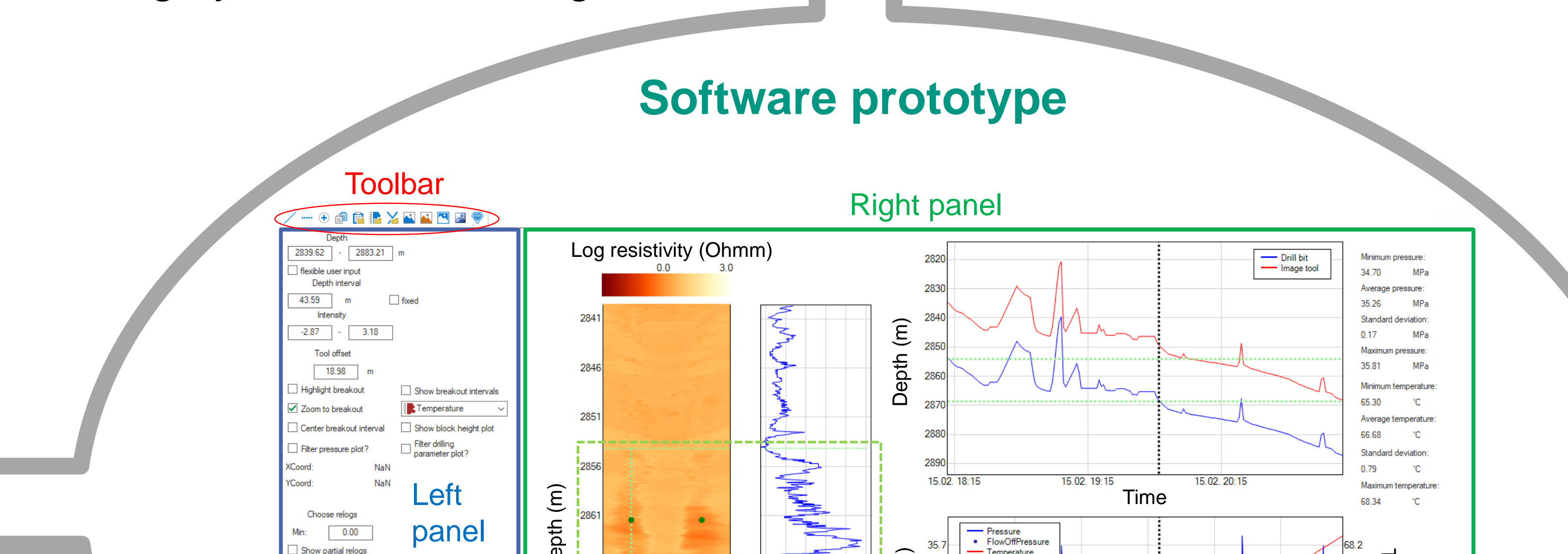

Temporal breakout evolution

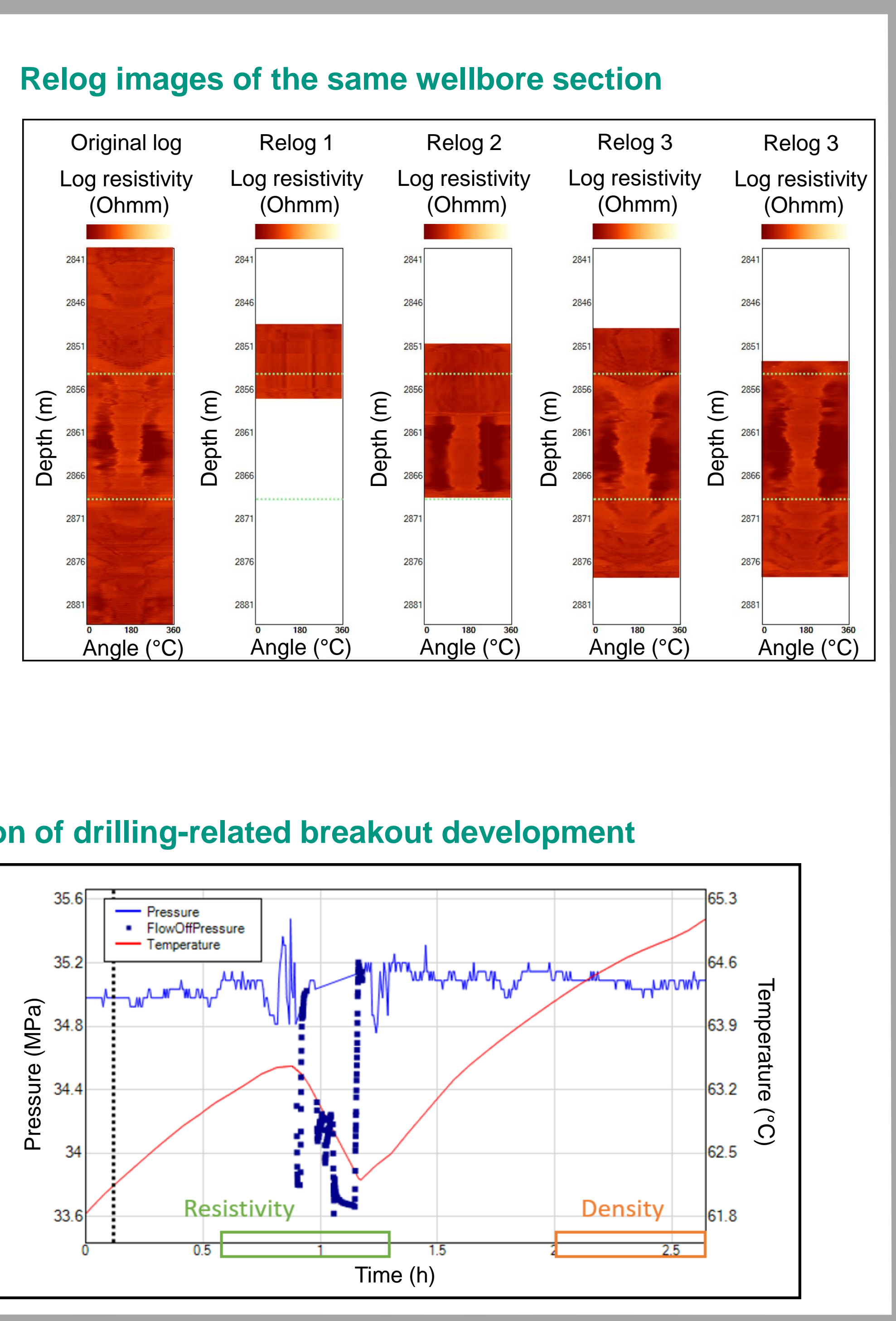

Observations of increased breakout depth extent and opening angles by using relog images

- Comparison of different images in the same BHA potentially enables the temporal analysis of breakout evolutions

Comparison of images for the identification of drilling-related breakout development

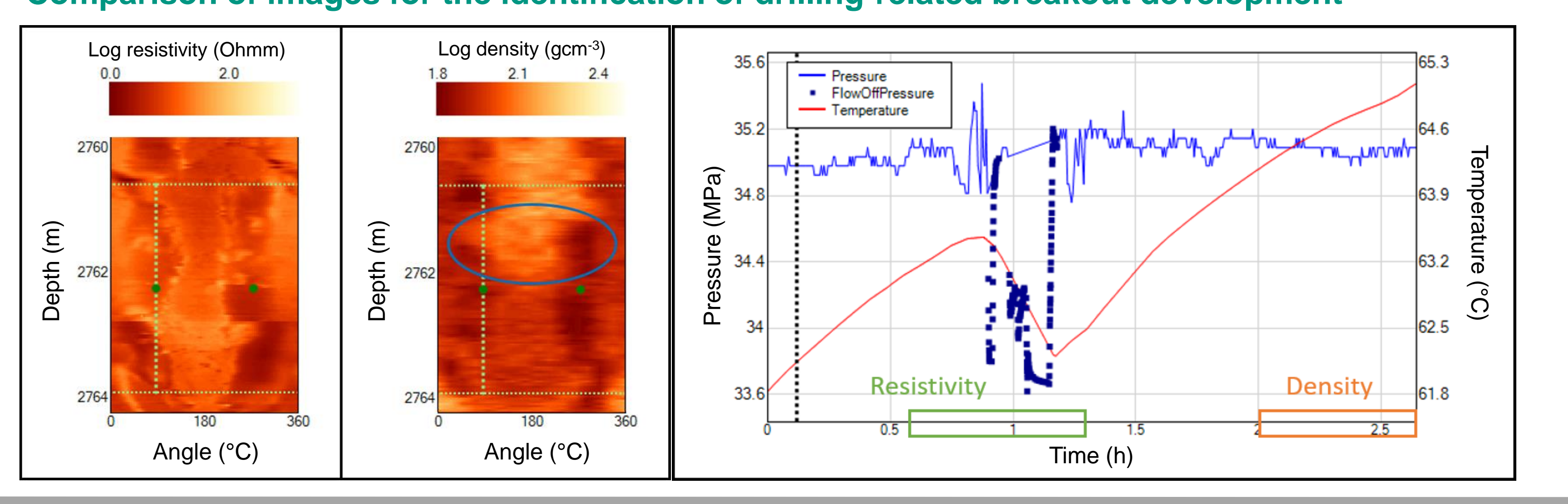

